FATEMEH HAGHIGHAT, M.Sc.

E-mail: Fa_haghighat_1@yahoo.com

Department of Industrial management,

Persian Gulf University

P.O. Box 7516913798, Bushehr, Iran
Traffic Planning

Preliminary Communication

Accepted: Aug. 4, 2010

Approved: July 6, 2011

\title{
APPLICATION OF A MULTI-CRITERIA APPROACH TO ROAD SAFETY EVALUATION IN THE BUSHEHR PROVINCE, IRAN
}

\begin{abstract}
Road safety is one of the influential factors in reducing road accidents and the resulting injuries and fatalities. The aim of this study is to determine the safety position of the roads of the Bushehr province based on various quantitative and qualitative criteria. For this purpose, a Multi-Criteria Decision Making (MCDM) approach has been utilized. In this approach, first all criteria influencing road safety in the Bushehr province were classified into main and sub-criteria groups and their weights were obtained using Group Analyt ic Hierarchy Process (GAHP). Then, the rankings of the Bushehr province roads were calculated through the Technique for Order Preference by Similarity to Ideal Solution (TOPSIS). The results indicate that during the period of investigation, the roads of Bushehr-Borazjan and Borazjan-Genaveh were the best with minor difference and Deylem-Behbahan road was the worst road of this province. In this regard, the criteria of violations/traffic and road facilities contribute more to the results due to their weights. It is clear that continuous evaluation of road safety will have significant effect on governmental policy-makings for improving roads and safetyrelated actions.
\end{abstract}

\section{KEY WORDS}

Roads Safety Coefficient, quantitative and qualitative criteria, Multi Criteria Decision Making (MCDM), GAHP Technique, TOPSIS Method

\section{INTRODUCTION}

Road accidents are considered as an important economic and social issue and have always been one of the most important concerns of the responsible officials and institutions.

The statistics of road accidents and the resulting injuries and fatalities is very high in Iran. Iran, with estimated 44 RTI (Road traffic injuries) deaths per 100,000 citizens in 2002 had higher RTI death rate than any other country for which reliable estimates can be made. For the sake of comparison, some examples on RTI mortality rate per 100,000 citizens is provided: in the United States 19 persons in 100,000 population die of road traffic injuries. In Eastern Mediterranean and North African countries, the World Health Organization (WHO) epidemiological region in which Iran is also placed, this number is 26 and in Sub-Saharan Africa the average number is 29. In Canada and Germany the RTI rates are 9 per 100,000 population and 6 per 100,000 population, respectively. Finally, the world average is about 19 fatalities per 100,000 population [1].

The Bushehr province located in the south of Iran, which despite its low land area and population has by itself accounted for almost $2 \%$ of accident statistics in Iran, has faced a considerable increase in the statistics related to road accidents and the resulting injuries and fatalities. Increase in this statistics, in turn, results in the increase in the number of unintentional deaths in accidents, increase in the percentage of bed occupation in hospitals by the injured, and in general, increase in the treatment expenses, social expenditures, and other governmental as well as non-governmental expenditures. Consequently, attempts for reducing the factors influencing road accidents and the resulting injuries and fatalities in this province will have major role in reducing the above-mentioned expenditures.

Providing safety of roads is one of the factors which exert influence upon the reduction of road accidents and the resulting injuries and fatalities. Thus, identification of the safety criteria of the roads and evaluation and ranking the roads on the basis of these criteria will be effective in fulfilling this goal.

Determining the safety coefficients of the roads according to the safety criteria will allow the drivers to determine their path to the destination using the information on the safety condition of each road. It is possible for a road to have a shorter distance to the destination but not to be at the standard level of safety, so the passengers can use an alternative path with a longer distance but higher safety. In case there is no alternative path, the drivers, knowing the safety condition of the road, will act more cautiously in observing the safety measures. Also, after having determined the safety condition of a road, if it becomes clear that it has a low 


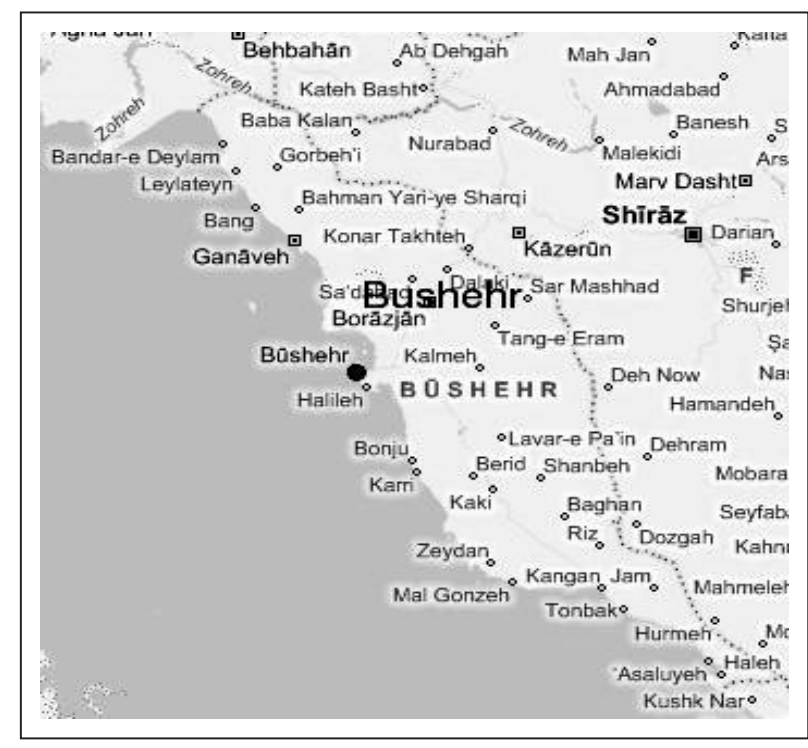

Figure 1 - The map of the Bushehr province

safety coefficient or lacks the safety standards required for vehicle traffic, laws and regulations can be passes for limiting or even forbidding traffic on that road and efforts can be made in order to promote the level of safety criteria. The possibility of proper management of the roads is provided for the police through ranking the roads according to various safety criteria.

The Bushehr province with an area of 23,167 square $\mathrm{km}$ is located in the Persian Gulf in the south of Iran and comprises 9 municipalities (Figure 1). The 11 main roads in the Bushehr province connect these municipalities with each other. The length of each road is shown in Table 1.

This study provides first a review of the literature on ranking and evaluation of the roads. Then, the most important quantitative and qualitative safety-related criteria of the roads in the Bushehr province are introduced and their weights are determined through GAHP technique. In the next section, using TOPSIS method, the 11 main roads of the Bushehr province are ranked. Finally, after offering the results, the safety condition of the Bushehr province roads is discussed.

\section{LITERATURE REVIEW}

In this section, the research dealing with analysis and evaluation of road safety is introduced.
Saaty [2] applies the Analytic Hierarchy Process (AHP) to transportation planning with multiple criteria. Tabucanon and Lee [3] use the AHP to evaluate rural highway improvement projects using tangible and intangible criteria. Kulkarni et al. [4] use a multi-attribute penalty function to evaluate and rank the overall impact of alternative highway alignments.

Milton et al. [5] demonstrate a modelling approach that can be used to better understand the injury-severity distributions of accidents on highway segments, and the effect that traffic, highway and weather characteristics have on these distributions. Results show that the mixed logit model shows considerable promise as a methodological tool in highway safety programming.

Lambert et al. [6] demonstrate the synthesis of relevant quantitative and qualitative evidence for accident analysis and for planning a large and diverse portfolio of highway investment projects. The proposed approach is adaptable to other topics in accident analysis and prevention that involve the use of quantitative and qualitative evidence, risk analysis, and multicriteria decision-making for project portfolio selection.

Elvik [7] presents the results of a survey of operational definitions of hazardous road locations in some European countries. The operational definitions of hazardous road locations used in these countries were compared in terms of six characteristics: referring to population of similar sites, relying on a sliding window approach, referring to a normal level of safety, recorded or expected number of accidents, accident severity considerations and the length of the period used to identify hazardous road locations.

Elvik [8] analyses how setting priorities for road safety strictly according to cost-benefit analysis would affect the provision of road safety in Norway and Sweden. In this paper, a number of sources of inefficiency in road safety policy are identified. These include: (a) lack of power, (b) the existence of social dilemmas, and (c) priority given to other policy objectives, in particular regional development.

Miaou and Song [9] explore some of the issues raised in recent roadway safety studies regarding ranking methodologies in light of the recent statistical development in space-time Generalized Linear Mixed Models (GLMM). They review the general ranking approaches and show how multivariate spatial GLMM can be used to model traffic crashes of several injury

Table 1 - The length of roads in the Bushehr province $(\mathrm{km})$

\begin{tabular}{|c|c|c|c|c|c|c|c|c|c|c|c|c|}
\hline Roads & 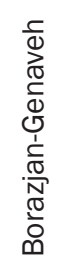 & 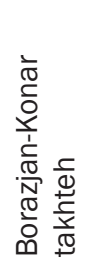 & $\begin{array}{l}\frac{c}{0} \\
\frac{0}{N} \\
\frac{\pi}{0} \\
\overline{0} \\
\frac{1}{1} \\
\frac{1}{0} \\
\frac{5}{0} \\
\frac{5}{0} \\
\overline{0}\end{array}$ & 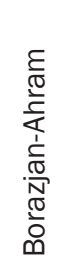 & 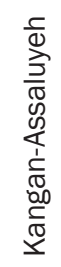 & 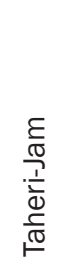 & 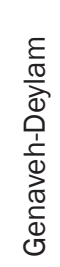 & 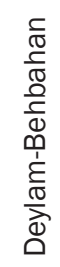 & 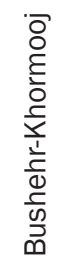 & 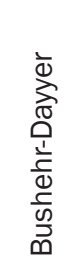 & 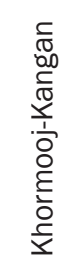 & $\begin{array}{l}\xi \\
心 \\
\omega\end{array}$ \\
\hline Length & 86 & 58 & 70 & 48 & 82 & 36 & 66 & 60 & 81 & 199 & 130 & 9916 \\
\hline
\end{tabular}


severity types simultaneously and how the model can be used within a Bayesian framework to rank sites by crash cost per vehicle-mile travelled (instead of by crash frequency rate).

Geurts et al. [10] perform a sensitivity analysis to investigate how big the impact would be on the current ranking of crash locations in Flanders (Belgium) when only taking into account the most serious injury per crash instead of all the injured occupants. Results show that this would lead to a different selection of $23.8 \%$ of the 800 sites that are currently considered as dangerous.

\section{METHODOLOGY}

In the present study, multi criteria decision making (MCDM) approach has been utilized for ranking the roads of the Bushehr province and determining their safety coefficients. Safety coefficient of each road means the relative closeness percent of that road (alternative) to ideal situation (closeness to ideal criteria that affect road safety). At the first stage, the most important criteria influencing safety coefficients of the Bushehr province roads were identified and classified into two groups of quantitative and qualitative types. At the next stage, the data relevant to each of these criteria for each road of the Bushehr province were collected from the related organizations. After data collection, in order to determine the weight and significance of every criterion, the criteria (quantitative and qualitative) were categorized into five main groups most of which have sub-criteria. Then, the weight of each criterion (main and sub-criterion) was determined through GAHP technique. After determining the weights of the criteria and their respective values for each road, the ranking of the roads and determination of their safety coefficients were performed at the next stage using TOPSIS method.

In this paper, GAHP technique was used because of its capability in combination with decision makers' ideas about weights of criteria. In addition, as the utility of considered criteria is uniformly increasing or decreasing, and in order to reduce the calculations volume of a large number of alternatives, we have used TOPSIS method for evaluation of considered alternatives (roads). Although we can use other MCDM techniques for evaluating the considered alternatives, however, using this technique is preferred because of its good comprehensibility for decision makers. In general, using these two techniques together reduces the number of required pair-wise comparisons, so using both of them simultaneously is a more appropriate option than other available options. The summary of research methodology of this study is depicted in Figure 2. In the following sections, each of these stages will be explained in detail.

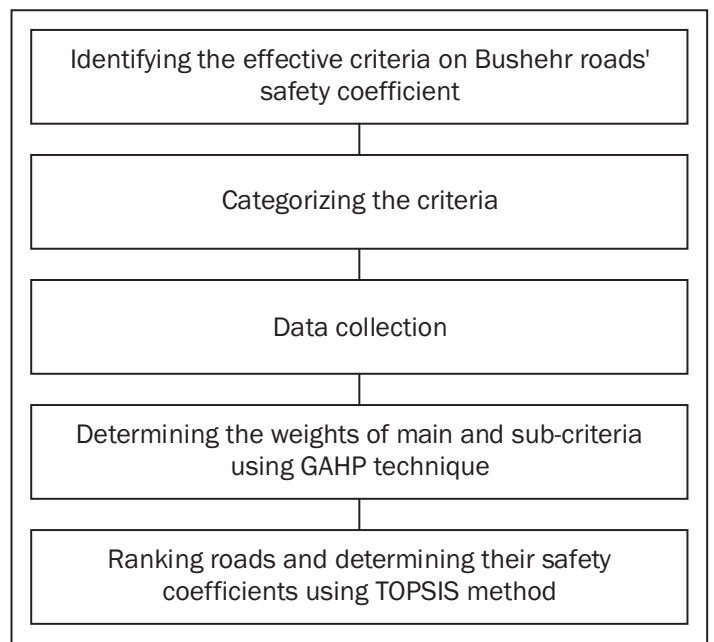

Figure 2 - Methodology of research

\section{CRITERIA INFLUENCING ROAD SAFETY}

So far, various measures or criteria have been employed for evaluation of the condition of the roads safety; for instance, Elvik [8, 11], classified road safety measures in four groups of road-related, vehicle-related, enforcement-related, and road user-related safety measures.

According to the experts' ideas in related organizations in the Bushehr province, there are 15 criteria that have the greatest effect on the safety condition of the Bushehr province roads. In the present study, these criteria are classified in two groups of quantitative and qualitative criteria which are introduced in the following. It should be mentioned that these criteria are mostly related to road features, road facilities, safety-related actions, traffic violations, and accidents occurred on the road, and do not include criteria related to vehicles and environmental factors such as climatic condition.

\subsection{Quantitative criteria related to road safety}

These criteria mostly include the number of accidents and their consequences relative to road traffic, drivers' violations relative to road traffic, safety-related actions, and some facilities and features of the road. In general, 12 important quantitative criteria were identified for determining the safety coefficient of the roads of the Bushehr province. These criteria are presented in Figure 3.

It is worth mentioning that since the degree of traffic and crowdedness differ on various roads, the safety condition of these roads, the criteria of violations, accidents and their consequences (injuries and fatalities) are calculated in relation to road traffic for better analysis and comparison. 


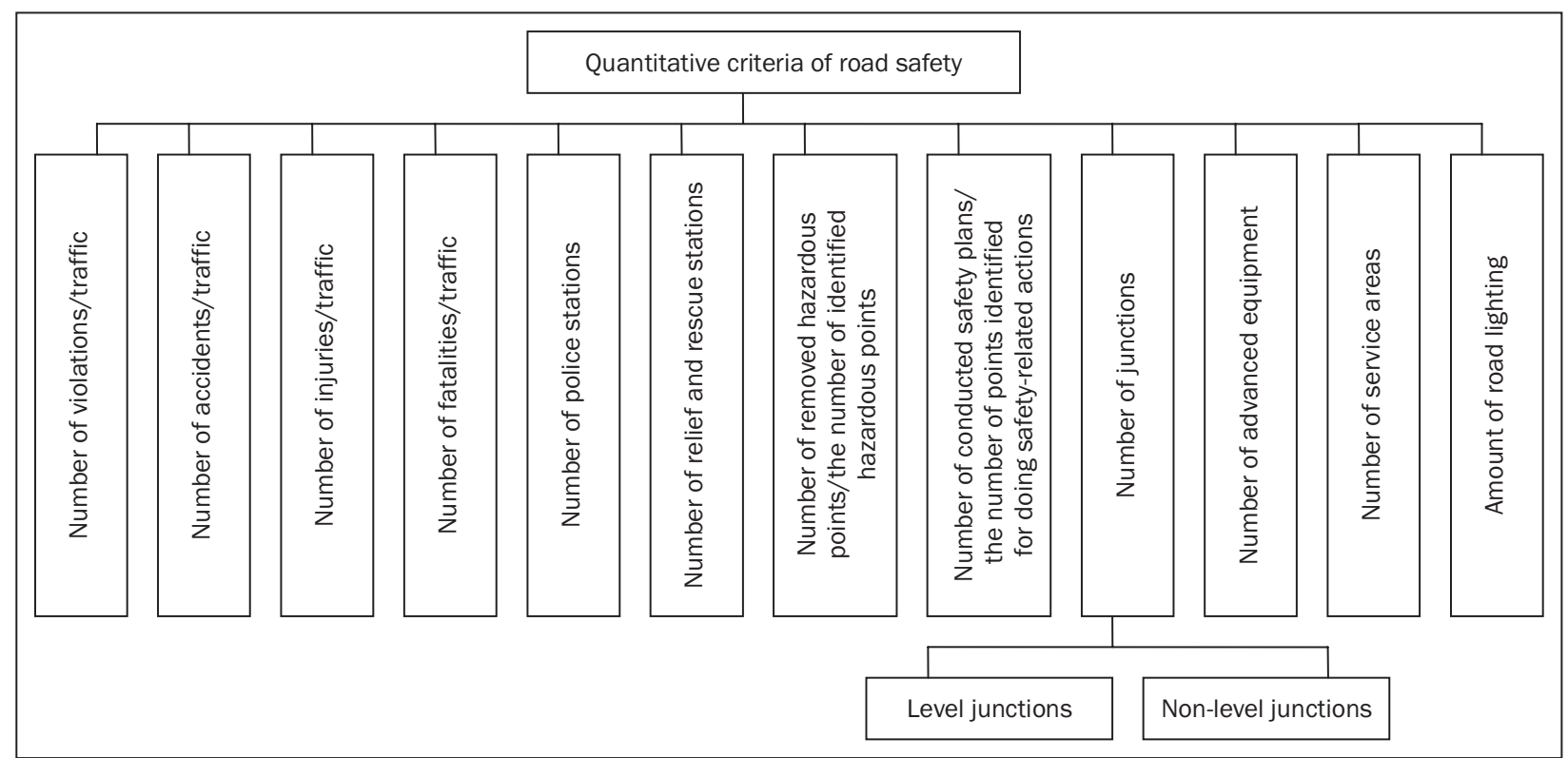

Figure 3 - Quantitative criteria related to roads safety

The criterion of the number of violations refers to the number of registered violations of traffic regulation by road users.

The criterion of removed hazardous points mainly includes the correction of road features at hazardous points, whereas road safety plans mostly include activities such as drawing road lines, installing lights at junctions, installing blinker, fencing the bridges, and installing guardrails. The criterion of the number of junctions is divided into two groups of level and nonlevel junctions, the former having positive and the latter having negative relationship with the increase of accidents. The criterion of the number of advanced equipment is meant to equip the road with advanced facilities like speed cameras, VMS signboards, satellite phones, etc. The roads of the Bushehr province are only equipped with the two first ones. In the end, the criterion of the amount of road lighting is measured on the base of the number of lights per 50 meters on each road.

\subsection{Qualitative criteria related to road safety}

Qualitative road safety criteria that mainly refer to the features or facilities of the road are indicated in Figure 4 . These criteria are considered qualitative in that their condition is subjectively determined based on the experts' views. All three qualitative criteria are positive ones, since the higher these criteria, the higher the road safety level and the lower the probability of accidents on the road. Among them, the criterion of road type is categorized into five types of highway, highwaymain road, main road, secondary road, and country road being safer, respectively. It should be pointed out that the most important roads of the Bushehr province

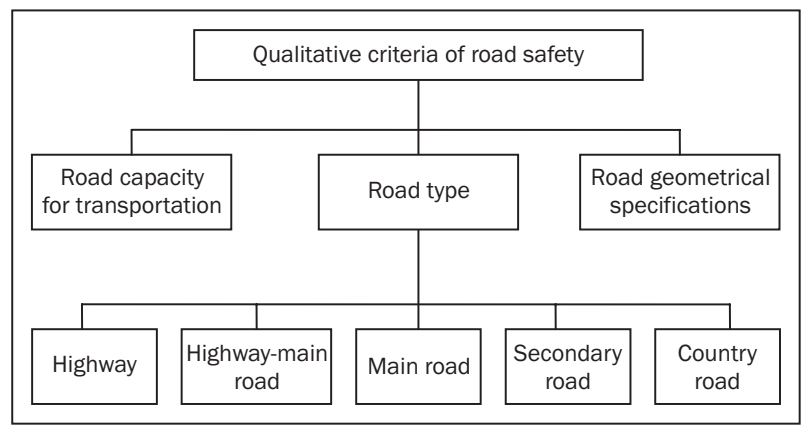

Figure 4 - Qualitative criteria related to road safety

are of the first four types and do not involve country road. Finally, the criterion of the road geometrical specifications refers to factors such as the design of the curve radius, the width of roadway, road shoulder, and earthwork gradient.

\section{DATA COLLECTION}

As previously mentioned, there are 11 main roads in the Bushehr province, so the data required for ranking and determining the safety coefficient of these roads on the basis of various quantitative and qualitative criteria were collected from four related organizations - Bushehr Transport and Terminals Organization (Department of safety and traffic), Bushehr Road and Transport Office (Department of road safety and boundary), Bushehr Police Office and Bushehr Emergency Ward. All the collected data relate to an 18-month period (2009/3/22 - 2010/9/22). Unfortunately, due to lack of a comprehensive information system for keeping the data on accidents and roads of the Bushehr province, the necessary data for all 
Table 2 - The value of quantitative criteria influencing the safety coefficient of the Bushehr province roads in the period of study

\begin{tabular}{|c|c|c|c|c|c|c|c|c|c|c|c|c|c|}
\hline \multirow{2}{*}{ Roads } & \multirow{2}{*}{ 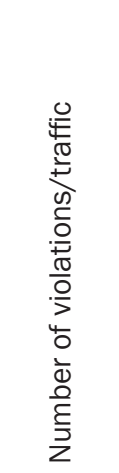 } & \multirow{2}{*}{ 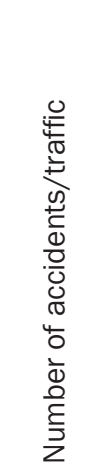 } & \multirow{2}{*}{ 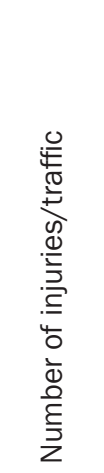 } & \multirow{2}{*}{ 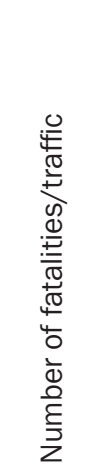 } & \multirow{2}{*}{ 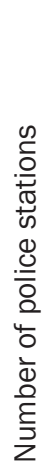 } & \multirow[b]{2}{*}{ 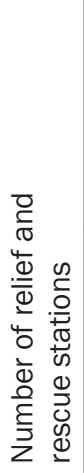 } & \multirow{2}{*}{ 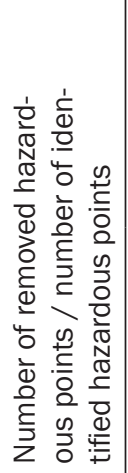 } & \multirow{2}{*}{ 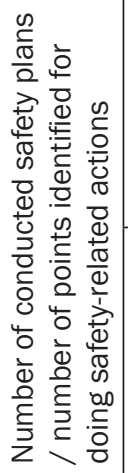 } & \multicolumn{2}{|c|}{ 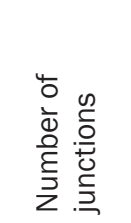 } & \multirow{2}{*}{ 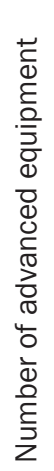 } & \multirow{2}{*}{ 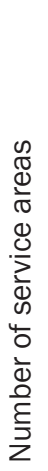 } & \multirow{2}{*}{ 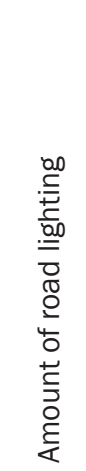 } \\
\hline & & & & & & & & & 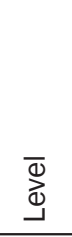 & $\begin{array}{l}\bar{d} \\
\frac{d}{1} \\
\frac{1}{2} \\
\frac{1}{2}\end{array}$ & & & \\
\hline Borazjan-Genaveh & 1.147 & 0.007 & 0.007 & 0.001 & 1 & 1 & 0.250 & 1.375 & 17 & 1 & - & - & 750 \\
\hline Borazjan-Konar takhteh & 3.031 & 0.015 & 0.008 & 0.002 & 1 & 1 & 0.500 & 0.667 & 8 & 3 & - & 1 & 1,050 \\
\hline Bushehr-Borazjan & 1.394 & 0.011 & 0.005 & 0.001 & 1 & 1 & 0.500 & 0.750 & 15 & 5 & 4 & 1 & 1,200 \\
\hline Borazjan-Ahram & 0.906 & 0.011 & 0.005 & 0.000 & - & 1 & 1.000 & 0.750 & 17 & - & - & - & 450 \\
\hline Kangan-Assaluyeh & 2.646 & 0.020 & 0.008 & 0.001 & 1 & 1 & 0.500 & 0.778 & 13 & 5 & - & - & 600 \\
\hline Taheri-Jam & 2.823 & 0.028 & 0.012 & 0.003 & 1 & 1 & 0.333 & 0.375 & 3 & 1 & - & - & 150 \\
\hline Genaveh-Deylam & 1.894 & 0.010 & 0.007 & 0.001 & - & 1 & 1.000 & 0.750 & 15 & - & - & 1 & 450 \\
\hline Deylam-Behbahan & 4.355 & 0.030 & 0.010 & 0.002 & - & 1 & 0.000 & 1.000 & 3 & - & - & - & 450 \\
\hline Bushehr-Khormooj & 3.033 & 0.017 & 0.011 & 0.002 & 1 & 1 & 1.000 & 0.600 & 13 & - & 1 & - & 600 \\
\hline Bushehr-Dayyer & 1.648 & 0.029 & 0.016 & 0.004 & - & 2 & 0.200 & 0.694 & 54 & - & - & 1 & 450 \\
\hline Khormooj-Kangan & 2.338 & 0.020 & 0.012 & 0.002 & - & 2 & 0.500 & 0.696 & 33 & - & - & 1 & 450 \\
\hline Sum & 25.216 & 0.197 & 0.099 & 0.018 & 6 & 13 & 5.783 & 8.435 & 191 & 15 & 5 & 5 & 6,600 \\
\hline
\end{tabular}

Table 3 - The value of qualitative criteria influencing the safety coefficient of the Bushehr province roads in the period of study

\begin{tabular}{|c|c|c|c|c|c|c|c|}
\hline \multirow[b]{2}{*}{ Roads } & \multirow{2}{*}{ 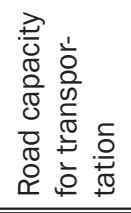 } & \multirow{2}{*}{ 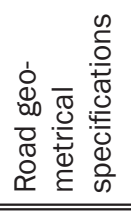 } & \multicolumn{5}{|c|}{ Road type } \\
\hline & & & 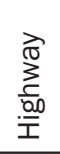 & 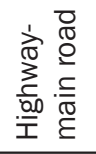 & 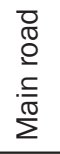 & 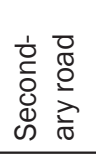 & $\begin{array}{l}\stackrel{Z}{*} \\
\stackrel{0}{0} \\
0 \\
0 \\
0\end{array}$ \\
\hline Borazjan-Genaveh & 5 & 7 & - & - & 7 & - & - \\
\hline Borazjan-Konar takhteh & 5 & 6 & - & 8 & - & - & - \\
\hline Bushehr-Borazjan & 4 & 7 & 9 & - & - & - & - \\
\hline Borazjan-Ahram & 4 & 5 & - & - & 7 & - & - \\
\hline Kangan-Assaluyeh & 5 & 7 & 9 & - & - & - & - \\
\hline Taheri-Jam & 5 & 5 & 9 & - & - & - & - \\
\hline Genaveh-Deylam & 4 & 5 & - & - & 7 & - & - \\
\hline Deylam-Behbahan & 5 & 5 & - & - & 7 & - & - \\
\hline Bushehr-Khormooj & 5 & 7 & 9 & - & - & - & - \\
\hline Bushehr-Dayyer & 3 & 4 & - & - & - & 6 & - \\
\hline Khormooj-Kangan & 5 & 6 & 9 & - & - & - & - \\
\hline Sum & 50 & 64 & 45 & 8 & 28 & 6 & - \\
\hline
\end{tabular}

Table 4 - The 9-option interval scale for assigning values to qualitative criteria

\begin{tabular}{||c|c|c|c|c|c|c|c|c||}
\hline 1 & 2 & 3 & 4 & 5 & 6 & 7 & 8 & 9 \\
\hline \hline Very low & $\begin{array}{c}\text { Rather } \\
\text { very low }\end{array}$ & Low & Rather low & Average & Rather high & high & $\begin{array}{c}\text { Rather } \\
\text { very high }\end{array}$ & Very high \\
\hline
\end{tabular}


11 roads under study in the previous years were not available and the road safety analysis was conducted only on the basis of the data from the recent months. However, a longer period (e.g. about 3 years or more) should be considered for a better analysis and evaluation of the safety conditions of the Bushehr province roads. This aim will be achieved through the establishment and development of comprehensive databases by governmental officials.

The 11 main roads of the Bushehr province and the required data for ranking and determining the safety coefficient of these roads according to quantitative and qualitative criteria in the study period are presented in Tables 2 and 3, respectively.

As evident in Table 2, all quantitative criteria are presented in terms of numbers. The values of relative criteria are decimal and those of others are integers.

Table 3 includes the qualitative criteria influencing road safety coefficient. The views of safety, traffic, and road experts in the related organizations were utilized for assigning values to these criteria. A subjective 9-option interval scale shown in Table 4 was used for this purpose. Since all qualitative criteria are positive, higher values are indicators of better condition of these criteria. It should be pointed out about the criterion of road type that each road in the Bushehr province is located in one type of the given categories and each road type has its own value. For instance, if the roads are highways, the value of 9 is assigned to them, even if they are not the same in terms of quality and comfort. This is because the road quality is investigated in the criterion of geometrical features.

\section{DETERMINATION OF SAFETY CRITERIA WEIGHTS USING GROUP AHP (GAHP) TECHNIQUE}

In this paper, GAHP technique was utilized for determining the weights of factors influencing safety coefficients of the roads. This technique, since its invention, has been one of the most widely used multiple criteria decision-making tools [12]. One application of the AHP technique is obtaining the weights of various criteria in a decision-making process through pairwise comparisons among the criteria.

Comparisons of the criteria can be performed using pairwise matrices in which the decision maker fills the upper triangular elements with values obtained from a scale of verbal judgments [13]: (equal, moderately more, strongly more, very strongly more, extremely more). This scale has associated numerical judgments $(1,3,5,7,9)$ and compromises $(2,4,6,8)$ between Table 5 - $R$ I values these values. The lower triangular part of the matrix is completed with the reciprocal judgment values in the upper triangular part, obtaining a reciprocal matrix. The priorities from criteria pairwise matrices are obtained by calculating the principal eigenvector. Then, the eigenvector values must be normalized before using them in the next level [14].

It should be mentioned that when the views of two or more decision-makers are to be considered, the GAHP model can be employed. So, as in this study we have used the two experts' ideas about the weights of the considered criteria, using such a technique can be useful in order to combine their different ideas. In such cases, it is possible to obtain the geometrical mean of various experts' views $\left(X_{i j}^{\prime}\right)$ and to consider it as the main matrix. The following formula is used for this purpose:

$$
\begin{aligned}
X_{i j}^{\prime}= & \left(\prod_{l=1}^{k} X_{i j}^{l}\right)^{1 / k} i, j=1,2, \ldots, n ; \quad I=1,2, \ldots, k ; \\
& \text { and } i \neq j
\end{aligned}
$$

Where $I$ is the decision-maker number, $k$ is the number of decision-makers, and $(i, j)$ are the criteria or alternatives being compared.

After algebraic calculations of matrices, it is necessary to determine the consistency of pairwise matrices. In a reciprocal positive matrix, the largest eigenvalue is greater than or equal to its order. A reciprocal matrix $A$ is perfectly consistent if its largest eigenvalue is equal to the matrix order [13]. The consistency index $(\mathrm{Cl})$ is defined as:

$C l=\frac{\lambda_{\max }-n}{n-1}$

Where $\lambda_{\max }$ is the largest eigenvalue of matrix $A$ and $n$ its order.

Then, the consistency ratio $(\mathrm{CR})$ is calculated in the following way:

$C R=\frac{C l}{R l}$

Where RI is the Random Index obtained from 500 positive reciprocal matrices randomly created with Saaty's scale values [14]. The values of this index for different orders are shown in Table 5.

If the CR is small, about $10 \%$ or less, the eigenvector, $\mathrm{w}$, associated to the largest eigenvalue of $A$ is accepted. In other words, to determine if a pairwise matrix is consistent, its CR must be under 0.1 [13].

In this study, in order to calculate the weights of criteria influencing road safety coefficient, they were categorized into five main groups of road features, road facilities, accidents and their consequences/traffic, violations/traffic, and safety-related actions, some

\begin{tabular}{|c|c|c|c|c|c|c|c|c|c|c||}
\hline $\mathrm{n}$ & 1 & 2 & 3 & 4 & 5 & 6 & 7 & 8 & 9 & 10 \\
\hline $\mathrm{RI}$ & 0 & 0 & 0.58 & 0.90 & 1.12 & 1.24 & 1.33 & 1.41 & 1.45 & 1.51 \\
\hline
\end{tabular}




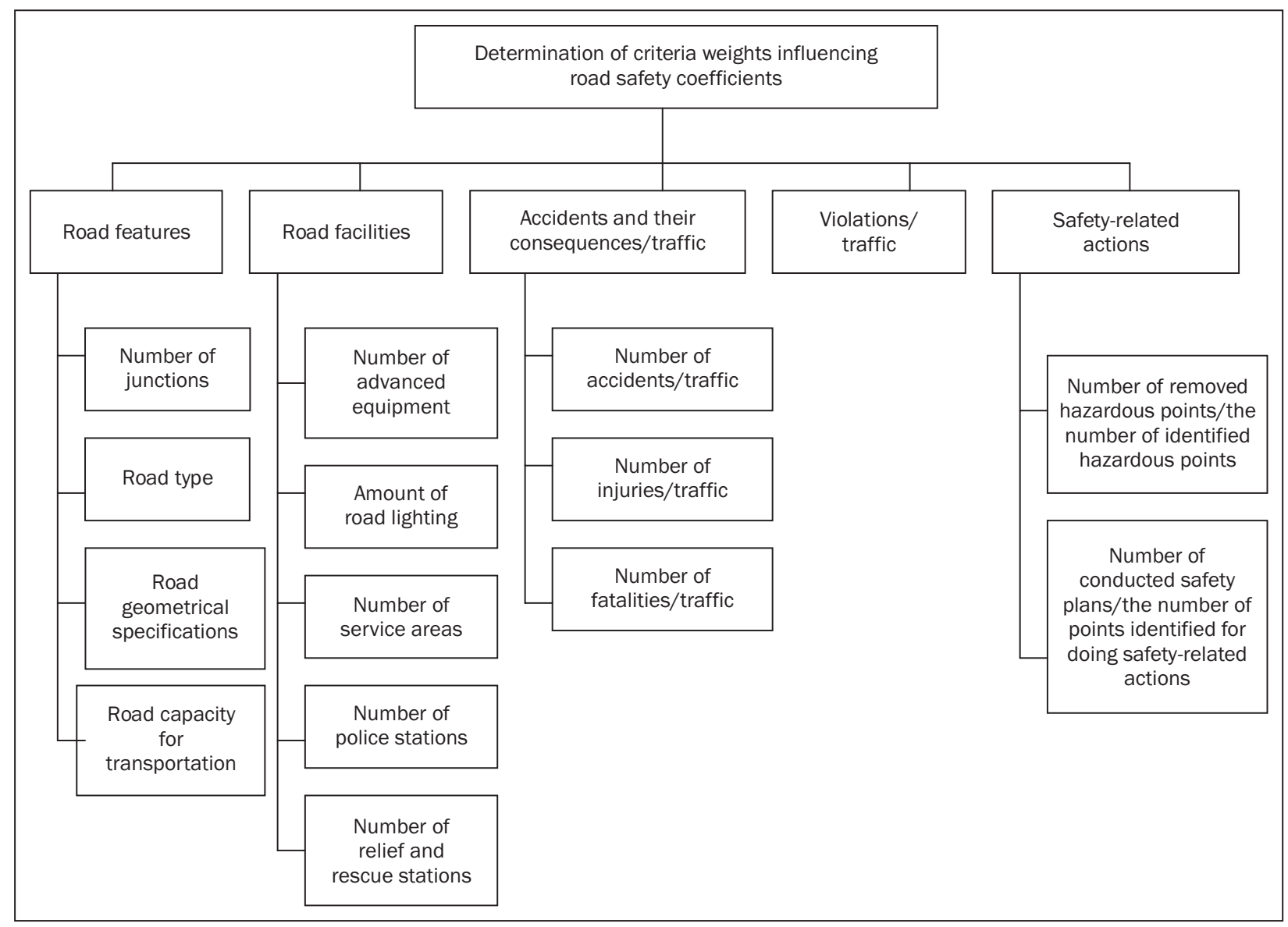

Figure 5 - The hierarchy of criteria influencing road safety coefficients

consisting of sub-criteria. The hierarchical diagram of criteria influencing road safety coefficient is shown in Figure 5. In this diagram, the main criteria are indicated in level 1 and the sub-criteria are shown in level 2. For determining the weights of the main criteria and sub-criteria using GAHP technique, four matrices of pairwise comparisons were created in order to compare the sub-criteria related to each category, and one pairwise comparison matrix was created for comparing all main criteria. The pairwise comparisons of criteria in these matrices were performed on the basis of the 9-option scale separately by two experts of Roads and Transportation Organizations skilled at safety issues. It should be noted that the weighting value of the experts' ideas was considered equal regarding their same positions in related organizations. Combining the views of these experts regarding the criteria, the combinational matrix of pairwise comparisons was obtained (appendix A). On the basis of criteria of this matrix, the main criteria and sub-criteria weights were determined.

The relative weights of criteria are obtained by normalizing each combinational matrix of pairwise comparison and getting the arithmetic mean of each row of the normalized matrix. The weights of the main criteria and sub-criteria, and compatibility rates resulting from the pairwise comparison of combinational matrices are presented in Tables 6 and 7, respectively. Since the compatibility rates of all matrices of pairwise comparison are less than 0.1 , the performed pairwise comparisons are acceptable and the weights obtained from these comparisons enjoy necessary validity.

As shown in Table 6, the criteria of violations/traffic, and accidents and their consequences / traffic are respectively the most important and the less important criteria among the main criteria influencing roads safety coefficient. The importance or weights of each sub-criterion are separately indicated in Table 7.

Table 6 - The weights of main criteria

\begin{tabular}{||l|l|c|}
\hline \multicolumn{1}{|c|}{$\begin{array}{c}\text { Importance } \\
\text { order }\end{array}$} & \multicolumn{1}{|c|}{ Main criteria } & Weights \\
\hline \hline 1 & Violations/traffic & 0.373 \\
\hline 2 & Road facilities & 0.202 \\
\hline 3 & Safety-related actions & 0.186 \\
\hline 4 & Road features & 0.137 \\
\hline 5 & $\begin{array}{l}\text { Accidents and their con- } \\
\text { sequences/traffic }\end{array}$ & 0.102 \\
\hline \hline Sum of weights & & 1 \\
\hline CR & & 0.075 \\
\hline
\end{tabular}


Table 7 - The weights of sub-criteria

\begin{tabular}{|c|c|c|c|c|}
\hline Main criteria & Sub-criteria & Weights & Sum of weights & $\mathrm{CR}$ \\
\hline \multirow{4}{*}{ Road features } & Number of junctions & 0.276 & \multirow{4}{*}{1} & \multirow{4}{*}{0.09} \\
\hline & Road type & 0.142 & & \\
\hline & Road geometrical specifications & 0.356 & & \\
\hline & Road capacity for transportation & 0.226 & & \\
\hline \multirow{5}{*}{ Road facilities } & Number of advanced equipment & 0.076 & \multirow{5}{*}{1} & \multirow{5}{*}{0.03} \\
\hline & Amount of road lighting & 0.251 & & \\
\hline & Number of service areas & 0.066 & & \\
\hline & Number of police stations & 0.225 & & \\
\hline & Number of relief and rescue stations & 0.382 & & \\
\hline Violations/traffic & - & - & - & - \\
\hline \multirow[b]{2}{*}{ Safety-related actions } & $\begin{array}{l}\text { Number of removed hazardous points/the } \\
\text { number of identified hazardous points }\end{array}$ & 0.500 & \multirow[b]{2}{*}{1} & \multirow[b]{2}{*}{0} \\
\hline & $\begin{array}{l}\text { Number of conducted safety plans/ } \\
\text { the number of points identified for } \\
\text { doing safety-related actions }\end{array}$ & 0.500 & & \\
\hline \multirow{3}{*}{$\begin{array}{l}\text { Accidents and their } \\
\text { consequences/traffic }\end{array}$} & Number of accidents/traffic & 0.079 & \multirow{3}{*}{1} & \multirow{3}{*}{0.04} \\
\hline & Number of injuries/traffic & 0.171 & & \\
\hline & Number of fatalities/traffic & 0.750 & & \\
\hline
\end{tabular}

\section{RANKING AND DETERMINING SAFETY COEFFICIENT OF THE BUSHEHR PROVINCE ROADS USING TOPSIS METHOD}

Now that the importance or weights of criteria influencing road safety are determined, it is possible to rank the roads of the Bushehr province according to their safety. The TOPSIS method was utilized in this paper for ranking the roads. In this section, the TOPSIS technique is briefly introduced and then its application and the results obtained from it for ranking the roads of the Bushehr province are presented.

\subsection{TOPSIS method}

The technique for order performance by similarity to ideal solution (TOPSIS), one of the known classical MCDM method, was first developed by Hwang and Yoon [15] for solving an MCDM problem [16]. It is based upon the concept that the chosen alternative should have the shorter distance from the positive ideal solution and the farthest from the negative ideal solution. The procedure of TOPSIS can be expressed in a series of steps [17]:

a. Calculate the normalized decision matrix (N). The normalized value $N_{i j}$ is calculated as:

$$
N_{i j}=X_{i j} / \sqrt{\sum_{j=1}^{n} X_{i j}^{2}}, i=1, \ldots, m, j=1, \ldots, n \text {. }
$$

b. Calculate the weighted normalized decision matrix (V). The weighted normalized value $V_{i j}$ is calculated as:

$V_{i j}=W_{i} N_{i j}, \quad i=1, \ldots, m, \quad j=1, \ldots, n$.

Where $W_{i}$ is the weight of the $i$-th attribute or criterion, and

$$
\sum_{i=1}^{m} W_{i}=1
$$

c. Determine the positive ideal and negative ideal solution. The positive ideal solution $(A+)$ for positive criteria includes the highest values of the criterion and for negative criteria it includes the lowest values of the criterion. In addition, the ideal negative solution (A-) for the positive and negative criteria includes the lowest and the highest values of the criterion, respectively.

$$
\begin{aligned}
& A^{+}=\left\{V_{1}^{+}, \ldots, V_{n}^{+}\right\}, \text {where } V_{j}^{+}=\left\{\begin{array}{l}
\operatorname{Max}_{i} V_{i j} \text { if } j \in K \\
\operatorname{Min}_{i} V_{i j} \text { if } j \in K^{\prime}
\end{array}\right. \\
& A^{-}=\left\{V_{1}^{-}, \ldots, V_{n}^{-}\right\}, \text {where } V_{j}^{-}= \begin{cases}\operatorname{Min}_{i} V_{i j} \text { if } j \in K \\
\operatorname{Max}_{i} V_{i j} \text { if } j \in K^{\prime}\end{cases}
\end{aligned}
$$

Where $i \in\{1,2, \ldots, m\}, j \in\{1,2, \ldots, n\}$ and $K$ is associated with the positive criteria, $K^{\prime}$ is associated with the negative criteria.

d. Calculate the separation measures, using the ndimensional Euclidean distance. The separation of each alternative from the positive ideal solution is given as: 


$$
d_{j}^{+}=\left\{\sum_{i=1}^{m}\left(V_{i j}-V_{i}^{+}\right)^{2}\right\}^{\frac{1}{2}}, j=1, \ldots, n \text {. }
$$

Similarly, the separation from the negative ideal solution is given as:

$d_{j}^{-}=\left\{\sum_{i=1}^{m}\left(V_{i j}-V_{i}^{-}\right)^{2}\right\}^{\frac{1}{2}}, j=1, \ldots, n$.

e. Calculate the relative closeness to the ideal solution. The relative closeness of the alternative $A_{j}$ with respect to $A^{+}$is defined as:

$R_{j}=d_{j}^{-} /\left(d_{j}^{+}+d_{j}^{-}\right), \quad j=1, \ldots, n$

Since $d_{j}^{+} \geq 0$ and $d_{j}^{-} \geq 0$, then, clearly, $R_{j} \in[0,1]$.

f. Rank the preference order. Ranking of alternatives is on the base of their $R_{j}$ values. Every alternative that has greater $R_{j}$ is better than the other alternatives.

\subsection{Results}

The evaluation and ranking of the Bushehr province roads were conducted regarding data presented in Tables 2 and 3. The value of each road was first determined and normalized on the base of sub-criteria. Then, through combination of the normalized values of sub-criteria, the normalized values of their respective main criteria were achieved that were used for ranking and evaluation besides other main criteria. In order to combine the normalized values of sub-criteria, the relative weight of each sub-criterion was multiplied by the value of their importance and then added up to each other. The results of such a combination are shown in Table 8. This table is called the normalized decision matrix $(\mathrm{N})$.

After obtaining the normalized decision matrix, the weighted normalized matrix $(\mathrm{V})$ was obtained through multiplication of this matrix by the diametrical matrix of the criteria weights, and the ideal positive and negative solutions ( $\mathrm{A}^{+}$and $\mathrm{A}^{-}$) were determined on the basis of this matrix. These solutions are presented in Table 9.

At the next stage, the distance of each alternative (road) to the positive and negative ideal solutions respectively shown by $\left(d_{j}^{+}\right)$and $\left(d_{j}^{-}\right)$was obtained based on which the relative closeness of each alternative to the ideal solution $\left(R_{j}\right)$ was achieved. The results of these calculations are presented in Table 10.

Since the values of $R_{j}$ are between 0 and 1 , it is possible to multiply the obtained values by 100 and consider the resulting values as the safety coefficient of the roads. The safety share of each road to the total is also determined in this table. As it was stated before, every alternative having higher $R_{j}$ is considered as a better one; thus, it can be claimed based on Table 10 that in the 18-month study period, the Bushehr-Borazjan and Borazjan-Genaveh roads with slight difference were the best and Deylam-Behbahan road was the worst road of the Bushehr province in terms of safety criteria. The low value of the criterion of violations/traffic (as the most important criterion) was influential in increasing the safety coefficient of the Bushehr-Borazjan and Borazjan-Genaveh roads. Regarding Deylam-Behbahan road as the least safe road of the Bushehr province, it can be stated that the criterion of violations/traffic having higher weight in comparison

Table 8 - Normalized matrix including the main criteria

\begin{tabular}{||l|c|c|c|c|c||}
\hline \multicolumn{1}{|c|}{ Criteria type } & Positive & Positive & Negative & Negative & Positive \\
\hline Roads criteria & Road features & Road facilities & $\begin{array}{c}\text { Accidents and } \\
\text { their conse- } \\
\text { quences/traffic }\end{array}$ & Violations/traffic & $\begin{array}{c}\text { Safety-related } \\
\text { actions }\end{array}$ \\
\hline \hline Borazjan-Genaveh & 0.252 & 0.270 & 0.118 & 0.139 & 0.319 \\
\hline Borazjan-Konar takhteh & 0.305 & 0.334 & 0.270 & 0.367 & 0.247 \\
\hline Bushehr-Borazjan & 0.309 & 0.424 & 0.109 & 0.169 & 0.263 \\
\hline Borazjan-Ahram & 0.184 & 0.144 & 0.092 & 0.110 & 0.384 \\
\hline Kangan-Assaluyeh & 0.326 & 0.253 & 0.184 & 0.321 & 0.268 \\
\hline Taheri-Jam & 0.288 & 0.202 & 0.393 & 0.342 & 0.152 \\
\hline Genaveh-Deylam & 0.186 & 0.173 & 0.169 & 0.229 & 0.384 \\
\hline Deylam-Behbahan & 0.272 & 0.144 & 0.266 & 0.527 & 0.188 \\
\hline Bushehr-Khormooj & 0.238 & 0.271 & 0.290 & 0.367 & 0.356 \\
\hline Bushehr-Dayyer & 0.158 & 0.266 & 0.633 & 0.200 & 0.179 \\
\hline Khormooj-Kangan & 0.207 & 0.266 & 0.316 & 0.283 & 0.252 \\
\hline \hline
\end{tabular}

Table 9 - Positive ideal and negative ideal solutions

\begin{tabular}{||l|l|l|l|l|l||}
\hline Positive ideal solutions $\left(A^{+}\right)$ & 0.045 & 0.086 & 0.009 & 0.041 & 0.071 \\
\hline Negative ideal solutions $\left(A^{-}\right)$ & 0.022 & 0.029 & 0.065 & 0.197 & 0.028 \\
\hline
\end{tabular}


Table 10 - Values $d_{j}^{+}, d_{j}^{-}$and $R_{j}$ for alternatives

\begin{tabular}{||l|c|c|c|c|c||}
\hline \multicolumn{1}{|c|}{ Alternatives (Roads) } & $d_{j}^{+}$ & $d_{j}^{-}$ & $R_{j}$ & $\begin{array}{c}\text { Safety coef- } \\
\text { ficients }\end{array}$ & $\begin{array}{c}\text { Safety share } \\
\text { percent }\end{array}$ \\
\hline \hline Borazjan-Genaveh & 0.037 & 0.160 & 0.813 & 81.3 & 13.11 \\
\hline Borazjan-Konar takhteh & 0.103 & 0.084 & 0.451 & 45.1 & 7.27 \\
\hline Bushehr-Borazjan & 0.032 & 0.158 & 0.832 & 83.2 & 13.41 \\
\hline Borazjan-Ahram & 0.060 & 0.171 & 0.740 & 74.0 & 11.93 \\
\hline Kangan-Assaluyeh & 0.089 & 0.098 & 0.523 & 52.3 & 8.43 \\
\hline Taheri-Jam & 0.111 & 0.076 & 0.407 & 40.7 & 6.56 \\
\hline Genaveh-Deylam & 0.071 & 0.129 & 0.645 & 64.5 & 10.40 \\
\hline Deylam-Behbahan & 0.171 & 0.041 & 0.194 & 19.4 & 3.12 \\
\hline Bushehr-Khormooj & 0.104 & 0.084 & 0.447 & 44.7 & 7.20 \\
\hline Bushehr-Dayyer & 0.085 & 0.125 & 0.596 & 59.6 & 9.60 \\
\hline Khormooj-Kangan & 0.081 & 0.102 & 0.556 & 55.6 & 8.96 \\
\hline \hline
\end{tabular}

to other main criteria, enjoys higher values compared to other roads. At the same time, the safety measures have not been taken sufficiently into consideration on this road, and it does not enjoy appropriate facilities.

\section{CONCLUSION}

Determination of the safety condition of the roads on the basis of various criteria will be useful in governmental decision-makings for planning and improving the road conditions. In this respect, the present study was aimed at ranking and determining the safety coefficient of the roads in the Bushehr province according to various quantitative and qualitative criteria. In the present study, first the factors influencing road safety coefficients were categorized into two categories of the main criteria and sub-criteria and the weight of each criterion was obtained using GAHP technique. Then, utilizing the TOPSIS method, the safety ranking of each road and its safety position were specified. On the basis of available rankings and decision-making matrix of the main criteria, it is possible to analyze the roads condition and enhance the values of positive criteria. It is also possible to reduce the values of negative criteria in the roads which have had lower safety coefficients in the period of study. The results of the present research show that during the 18-month period of study, the Bushehr-Borazjan and BorazjanGenaveh roads with slight difference were the best and Daylam-Behbahan road was the worst road of the Bushehr province based on all criteria influencing safety coefficients. It is clear that by increasing the length of the study period and updating the values of the criteria, a better analysis of the roads condition can be performed.

Furthermore, although other criteria could be considered for determination of the safety level of the roads of the Bushehr province, due to lack of a comprehensive information system about the roads and accidents, as well as lack of advanced equipments such as GPS in this province, only the most important quantitative and qualitative criteria influencing road safety were considered. It is evident that by removing these barriers and using the views of more experts for a more accurate determination of the weights of the influencing criteria, a more comprehensive evaluation of the safety condition of the Bushehr province roads can be conducted.

\section{ACKNOWLEDGMENT}

I would like to express my gratitude to the members of safety and traffic department of Bushehr Transportation and Terminals Organization, the Department of safety and boundary of Bushehr Roads and Transportation Office, Bushehr Police Office, and Emergency Ward of Bushehr for their contribution in data collection and offering useful explanations.

\section{APPENDIX A}

The combinational matrices of pairwise comparisons

The combinational matrix of pairwise comparisons regarding accidents and their consequences/traffic criteria

\begin{tabular}{|l|c|c|c||}
\hline \multicolumn{1}{|c|}{ Criteria } & Number of accidents/traffic & Number of injuries/traffic & Number of fatalities/traffic \\
\hline \hline Number of accidents/traffic & 1 & 0.333 & 0.143 \\
\hline Number of injuries/traffic & 3 & 1 & 0.167 \\
\hline Number of fatalities/traffic & 7 & 6 & 1 \\
\hline
\end{tabular}


The combinational matrix of pairwise comparisons regarding safety-related actions criteria

\begin{tabular}{||l|c|c||}
\hline \multicolumn{1}{|c|}{ Criteria } & $\begin{array}{c}\text { Number of removed hazard- } \\
\text { ous points/the number of } \\
\text { identified hazardous points }\end{array}$ & $\begin{array}{c}\text { Number of conducted safety plans/ } \\
\text { the number of points identified } \\
\text { for doing safety-related actions }\end{array}$ \\
\hline \hline $\begin{array}{l}\text { Number of removed hazardous points/the } \\
\text { number of identified hazardous points }\end{array}$ & 1 & 1 \\
\hline $\begin{array}{l}\text { Number of conducted safety plans/the number of } \\
\text { points identified for doing safety-related actions }\end{array}$ & 1 & 1 \\
\hline \hline
\end{tabular}

The combinational matrix of pairwise comparisons regarding road features criteria

\begin{tabular}{||l|c|c|c|c||}
\hline \multicolumn{1}{|c|}{ Criteria } & $\begin{array}{c}\text { Number of } \\
\text { junctions }\end{array}$ & Road type & $\begin{array}{c}\text { Road geometrical } \\
\text { specifications }\end{array}$ & $\begin{array}{c}\text { Road capacity for } \\
\text { transportation }\end{array}$ \\
\hline \hline Number of junctions & 1 & 3.464 & 0.707 & 0.707 \\
\hline Road type & 0.289 & 1 & 0.632 & 0.707 \\
\hline Road geometrical specifications & 1.414 & 1.581 & 1 & 2.449 \\
\hline Road capacity for transportation & 1.414 & 1.414 & 0.408 & 1 \\
\hline
\end{tabular}

The combinational matrix of pairwise comparisons regarding road facilities criteria

\begin{tabular}{||l|c|c|c|c|c||}
\hline \multicolumn{1}{|c|}{ Criteria } & $\begin{array}{c}\text { Number of } \\
\text { advanced } \\
\text { equipment }\end{array}$ & $\begin{array}{c}\text { Amount of } \\
\text { road lighting }\end{array}$ & $\begin{array}{c}\text { Number of } \\
\text { service areas }\end{array}$ & $\begin{array}{c}\text { Number of } \\
\text { police stations }\end{array}$ & $\begin{array}{c}\text { Number of relief } \\
\text { and rescue } \\
\text { stations }\end{array}$ \\
\hline \hline Number of advanced equipment & 1 & 0.316 & 1 & 0.250 & 0.289 \\
\hline Amount of road lighting & 3.162 & 1 & 4.243 & 1 & 0.775 \\
\hline Number of service areas & 1 & 0.236 & 1 & 0.258 & 0.204 \\
\hline Number of police stations & 4 & 1 & 3.873 & 1 & 0.333 \\
\hline Number of relief and rescue stations & 3.464 & 1.291 & 4.899 & 3 & 1 \\
\hline
\end{tabular}

The combinational matrix of pairwise comparisons regarding all main criteria

\begin{tabular}{||l|c|c|c|c|c||}
\hline \multicolumn{1}{|c|}{ Criteria } & $\begin{array}{c}\text { Road } \\
\text { features }\end{array}$ & $\begin{array}{c}\text { Road } \\
\text { facilities }\end{array}$ & $\begin{array}{c}\text { Accidents and their } \\
\text { consequences/traffic }\end{array}$ & $\begin{array}{c}\text { Violations/ } \\
\text { traffic }\end{array}$ & $\begin{array}{c}\text { Safety-related } \\
\text { actions }\end{array}$ \\
\hline \hline Road features & 1 & 0.926 & 1.155 & 0.267 & 1 \\
\hline Road facilities & 1.080 & 1 & 1.155 & 1.118 & 1 \\
\hline Accidents and their consequences/traffic & 0.866 & 0.866 & 1 & 0.224 & 0.333 \\
\hline Violations/traffic & 3.742 & 0.894 & 4.472 & 1 & 2.449 \\
\hline Safety-related actions & 1 & 1 & 3 & 0.410 & 1 \\
\hline
\end{tabular}

\section{LITERATURE}

[1] Naghavi, M., Shahraz, S., Bhalla, K., Jafari, N., Pourmalek, F., Bartels, D., Puthenpurakal, J.A., Motlagh, M.A.: Adverse health outcomes of road traffic injuries in Iran after rapid motorization, Arch Iranian Med, Vol. 12, No. 3, 2009, pp. 284-294

[2] Saaty, T.L.: Transport planning with multiple criteria: the analytic hierarchy process applications and progress review, Journal of Advanced Transport, Vol. 29, No. 1, 1995, pp. 81-126

[3] Tabucanon, M.T., Lee, H.M.: Multiple criteria evaluation of transportation system improvement projects: the case of Korea, Journal of Advanced Transport, Vol. 29, 1995, pp. 127-143

[4] Kulkarni, R.B., Burns, R.L., Wright, J., Apper, B., Baily, T.O., Noack, S.T.: Decision analysis of alternative high- way alignments, Transport Engineering, Vol. 119, No. 3, 1993, pp. 317-332

[5] Milton, J.C., Shankar, V.N., Mannering, F.L.: Highway accident severities and the mixed logit model: An exploratory empirical analysis, Accident Analysis and Prevention, Vol. 40, 2008, pp. 260-266.

[6] Lambert, J.H., Peterson, K.D., Joshi, N.N.: Synthesis of quantitative and qualitative evidence for accident Synthesis of quantitative and qualitative evidence for accident, Accident Analysis and Prevention, Vol. 38, 2006, pp. 925-935

[7] Elvik, R.: A survey of operational definitions of hazardous road locations in some European countries, Accident Analysis and Prevention, Vol. 40, 2008, pp. 1830-1835.

[8] Elvik, R.: How would setting policy priorities according to cost-benefit analyses affect the provision of road 
safety? , Accident Analysis and Prevention, Vol.35, 2003, pp. 557-570

[9] Miaou, S.P., Song, J.J.: Bayesian ranking of sites for engineering safety improvements: Decision parameter, treatability concept, statistical criterion, and spatial dependence, Accident Analysis and Prevention, Vol. 37, 2005, pp. 699-720

[10] Geurts, K., Wets, G., Brijs, T., Vanhoof, K., Karlis, D.: Ranking and selecting dangerous crash locations: Correcting for the number of passengers and Bayesian ranking plots, Journal of Safety Research, Vol. 37, 2006, pp. 83-91

[11] Elvik, R.: The trade-off between efficiency and equity in road safety policy, Safety Science, Vol. 47, 2009, pp. 817-825

[12] Vaidya, O.S., Kumar, S.: Analytic hierarchy process: An overview of applications, European Journal of Operational Research, Vol. 169, 2006, pp. 1-29
[13] Saaty, T.L.: The Analytic Hierarchy Process, McGrawHill, New York, 1980

[14] Gomez-Ruiz, J.A., Karanik, M., Pelaez, J.I.: Improving the Consistency of AHP Matrices Using a Multi-layer Perceptron-Based Model, J. Cabestany et al. (Eds.): IWANN 2009, Part I, LNCS 5517, Springer-Verlag, Berlin, Heidelberg, 2009, pp. 41-48

[15] Hwang, C.L., Yoon, K.: Multiple Attribute Decision Making Methods and Applications, Springer, Berlin Heidelberg, 1981.

[16] Lai, Y.J., Liu, T.Y., Hwang, C.L.: TOPSIS for MODM, European Journal of Operational Research, Vol. 76, No. 3, 1994, pp. 486-500

[17] Jahanshahloo, G.R., Hosseinzadeh Lotfi, F. and Izadikhah, M.: An algorithmic method to extend TOPSIS for decision-making problems with interval data, Applied Mathematics and Computation, Vol. 175, 2006, pp. $1375-1384$ 